\section{IgE-Mediated Hypersensitivity to Lysine Clonixinate}

Villalón García AL, Pérez Pimiento A, López San Martín MG, Iglesias Cadarso A

Allergy Department, University Hospital Puerta de Hierro, Madrid, Spain

J Investig Allergol Clin Immunol 2021; Vol. 31(1): 67-68

doi: 10.18176/jiaci.0613

Key words: Lysine clonixinate. Drug allergy. Anti-inflammatory analgesics. Urticaria. IgE-mediated hypersensitivity.

Palabras clave: Clonixinato de lisina. Alergia a medicamentos. Analgésicos antiinflamatorios. Urticaria. Hipersensibilidad mediada por IgE.

Lysine clonixinate belongs to the nicotinic acid family, a family of nonsteroidal anti-inflammatory drugs (NSAIDs), which are in turn a class of antiprostaglandin drugs. At therapeutic doses, it acts mainly by inhibiting cyclooxygenase 2 (COX-2), whereas at lower doses, it inhibits cyclooxygenase $1(\mathrm{COX}-1)$. It is indicated as an analgesic and anti-inflammatory drug in patients with acute or chronic pain and has proven effective in various algic syndromes such as renal colic, nerve compression, muscular pain, and odontalgia [1]. It is generally administered orally, although it is also effective and well tolerated intravenously for the treatment of severe migraine attacks [1-3]. Little is known about cross-reactivity between nicotinic acid family anti-inflammatory drugs (lysine clonixinate, morniflumate, isonixin, and niflumic acid) in acute allergic reactions. Most are used as a useful alternative in patients with NSAID hypersensitivity [4]. Numerous studies compare the efficacy and tolerance profile of oral lysine clonixinate with that of other analgesics/NSAIDs [5-8]. Allergic reactions to lysine clonixinate are very rare, and there are no studies on this agent in the medical literature.

A 70-year-old woman had been prescribed lysine clonixinate for headache. Thirty minutes following the first 250-mg intake, she developed itching in the ears, armpits, and arms and, progressively, generalized rash without angioedema. She did not develop dyspnea, stomach pain, or other systemic symptoms. She was treated in the emergency department with antihistamines and intramuscular corticosteroids, and her symptoms resolved completely in 2 hours. A month later, she reported a reaction similar to that following the first $250-\mathrm{mg}$ intake. She subsequently tolerated paracetamol at $2 \mathrm{~g} / \mathrm{d}$. Skin prick test and single-blind, placebo-controlled oral challenge with lysine clonixinate, morniflumate, isonixin, niflumic acid, and acetylsalicylic acid were performed 2-3 months after the reaction and once written consent had been obtained.

The result of the skin prick test using lysine clonixinate dissolved in saline was positive $(4 \times 4 \mathrm{~mm}$, histamine control; saline serum, $0 \mathrm{~mm}$ ) (Figure). Skin prick testing with lysine clonixinate dissolved in saline was negative in 10 atopic patients and in 10 patients diagnosed with hypersensitivity

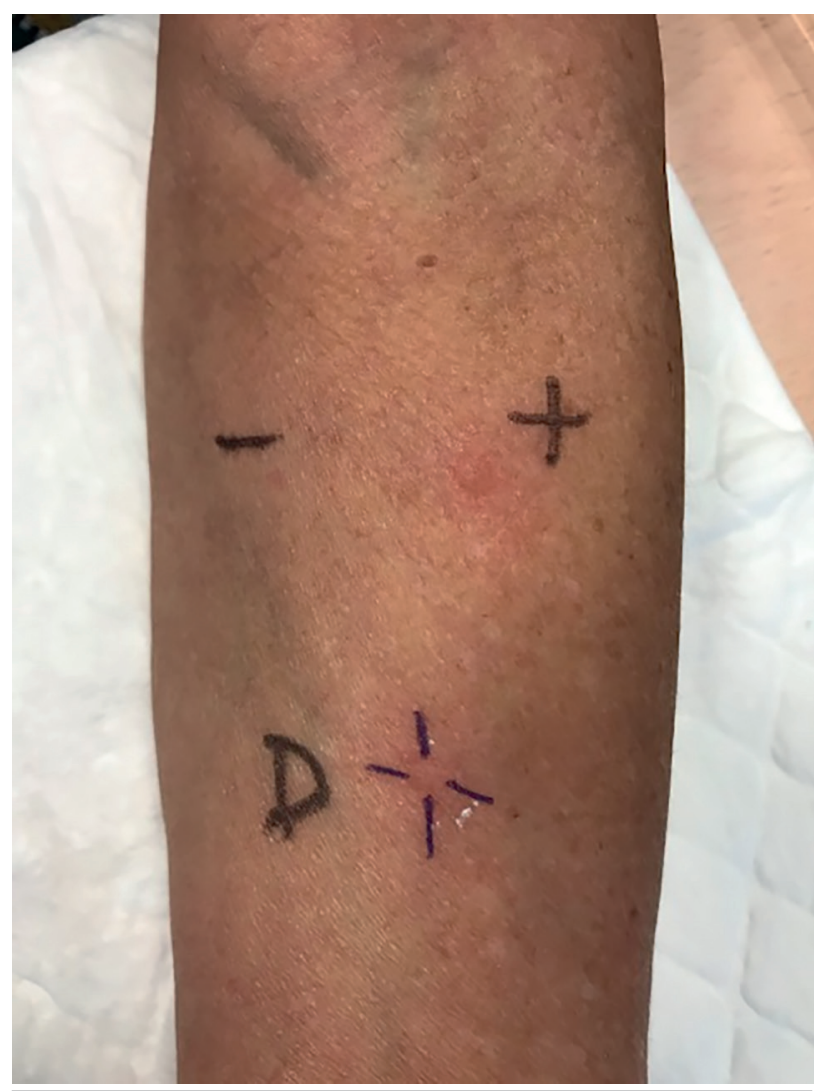

Figure. Skin prick test.

to NSAIDs. Oral challenge with lysine clonixinate was not performed. Skin prick testing with morniflumate, isonixin, niflumic acid, and acetylsalicylic acid dissolved in saline was negative. Oral challenge with acetylsalicylic acid $1 \mathrm{~g}$ was well tolerated. Oral challenges with morniflumate, isonixin, and niflumic acid were not performed, as these were not authorized by the patient.

Like all medicines NSAIDs can cause adverse effects, although not all patients experience the few adverse effects of lysine clonixinate [9]. Common adverse effects (which may affect up to 1 in 10 people) include discomfort, stomachache, nausea, vomiting, diarrhea, and minimal intestinal bleeding. Rare adverse effects (which may affect up to 1 in 1000 people) include stomach inflammation and vomiting with blood. Very rare adverse effects (which may affect up to 1 in 10000 people) include dizziness, hypersensitivity reactions (allergy) with rash and itchy skin, eczema, skin disorders, bronchospasm, breathing difficulties, insomnia, asphyxia, tremor, pharyngitis, fever, fatigue, lack of appetite, and blood disorders such as agranulocytosis, anemia, and thrombocytopenia. Interestingly, Kramer et al [10] reported that lysine clonixinate did not induce changes in platelet count or function when administered to healthy volunteers at the commonly used therapeutic doses.

We describe a patient with allergy to lysine clonixinate, which took the form of acute urticaria. The result of skin prick testing was positive, and the patient tolerated acetylsalicylic 
acid. Hypersensitivity to NSAIDs was ruled out. Crossreactivity between drugs from the nicotinic group could not be demonstrated, as the patient refused to undergo testing. Skin prick testing with lysine clonixinate is a useful tool for the diagnosis of immediate acute urticaria induced by sensitization to this drug. To our knowledge, this is the first report of a positive skin prick test result with lysine clonixinate in the medical literature. Our findings strongly suggest an IgE-mediated mechanism.

\section{Funding}

The authors declare that no funding was received for the present study.

\section{Conflicts of Interest}

The authors declare that they have no conflicts of interest.

\section{References}

1. Krymchantowski $A V$, Barbosa J. Intravenous lysine clonixinate for the treatment of migraine: an open pilot study. Arq Neuropsiquiatr. 1999.57(3A):606-9.

2. Krymchantowski AV, Silva MT. Intravenous lysine clonixinate for the acute treatment of severe migraine attacks: a doubleblind, randomized, placebo-controlled study. Curr Ther Res Clin Exp. 2003;64(8):505-13.

3. Krymchantowski AV, Barbosa JS, Cheim C, Alves LA. Oral lysine clonixinate in the acute treatment of migraine: a double-blind placebo-controlled study. Arq Neuropsiquiatr. 2001;59(1):469.

4. Mero F, Nettis E, Aloia AM, Di Leo E, Ferranini A, Vacca A. Short-term tolerability of morniflumate in patients with cutaneous hypersensitivity to non-steroidal anti-inflammatory drugs. Int J Immunopathol Pharmacol. 2013;26(1):247-50.

5. Perez-Urizar J, Martínez-Rider R, Torres-Roque I, GarrochoRangel A, Pozos-Guillen A. Analgesic efficacy of lysine clonixinate plus tramadol versus tramadol in multiple doses following impacted third molar surgery. Int J Oral Maxillofac Surg. 2014;43(3):348-54.

6. Noronha VR, Gurgel GD, Alves LC, Noman-Ferreira LC, Mendonça LL, Aguiar EG, et al. Analgesic efficacy of lysine clonixinate, paracetamol and dipyrone in lower third molar extraction: a randomized controlled trial. Med Oral Patol Oral Cir Bucal. 2009;14(8):e411-5.

7. Krymchantowski AV, Peixoto P, Higashi R, Silva A Jr, Schutz V. Lysine clonixinate vs naproxen sodium for the acute treatment of migraine: a double-blind, randomized, crossover study. Med Gen Med. 2005;7(4):69.

8. De los Santos AR, Di Girolamo G, Martí ML. Efficacy and tolerance of lysine clonixinate versus paracetamol/ codeine following inguinal hernioplasty. Int J Tissue React. 1998;20(2):71-81.

9. Franchi $A$, Di Girolamo $G$, Farina $M$, de los Santos $A R$, Martí ML, Gimeno MA. Differential action of non-steroidal antiinflammatory drugs on human gallbladder cyclooxygenase and lipoxygenase. Medicina (B Aires). 2000;60(5 Pt 1):580-6.
10. Kramer EH, Sassetti B, Kaminker AJ, De Los Santos AR, Martí ML, Di Girolamo G. Effects of lysine clonixinate on platelet function. Comparison with other non-steroidal antiinflammatory agents. Medicina (B Aires). 2001;61(3):301-7.

Manuscript received January 21, 2020; accepted for publication May 25, 2020

Ángel Luis Villalón García Allergy Department University Hospital Puerta de Hierro Calle Manuel de Falla, 1 28222 Majadahonda, Spain E-mail: anluvillalon@yahoo.es 